\title{
Chapter 20 \\ MIT Full STEAM Ahead: Bringing Project-Based, Collaborative Learning to Remote Learning Environments
}

\author{
Claudia Urrea, Kirky Delong, Joe Diaz, Eric Klopfer, Meredith Thompson, \\ Aditi Wagh, Jenny Gardony, Emma Anderson, and Rohan Kundargi
}

\begin{abstract}
With schools and educational centers around the country moving from in-person to emergency remote learning due to the COVID-19 pandemic, education faces an unprecedented crisis (Hodges et al., Educause Review 27, 2020). This case study presents the efforts and impact of Full STEAM Ahead (FSA) launched by the Massachusetts Institute of Technology (MIT) in response to the pandemic to support remote collaborative learning for K-12 learners, parents, and educators. We present two FSA initiatives: (1) weekly themed packages with developmentally appropriate activities for K-12 remote learning and (2) Full STEAM Ahead Into Summer (FSAIS), an online summer program for middle school Massachusetts students, specifically targeting students who are at risk for "COVID Slide." (Institutewide Task Force on the Future of MIT Education-Final Report: http://web.mit.edu/ future-report/TaskForceFinal_July28.pdf?) Our operative theory of change is that we can improve K-12 remote collaborative learning experiences through developing and sharing a curriculum that exemplifies the minds-on and hands-on approach advocated by MIT, strategically leveraging existing structures and projects within MIT, and establishing partnerships with the local and international community. We gauge the effect of these efforts on contributing members of the MIT community and targeted learners by analyzing data gathered through participant surveys and artifacts such as the website, packages, modules, and student projects created during the summer programs. Our findings indicate that existing structures and resources with community building - facilitated the achievement of our goal to develop and distribute problem-based learning activities and that interaction and community building were central in meeting those goals. This work contributes to the knowledge base regarding emergency online learning and the development of effective university outreach efforts.
\end{abstract}

C. Urrea $(\bowtie) \cdot$ K. Delong $\cdot$ J. Diaz $\cdot$ E. Klopfer $\cdot$ M. Thompson $\cdot$ A. Wagh

J. Gardony $\cdot$ E. Anderson $\cdot$ R. Kundargi

Massachusetts Institute of Technology, Cambridge, MA, USA

e-mail: calla@mit.edu 


\subsection{Introduction}

Within the short span of a few months in early 2020, the COVID-19 pandemic rapidly impacted and transformed the world. In mid-March, as schools and educational centers around the United States transitioned to emergency remote learning, education faced an unprecedented crisis (Hodges et al., 2020). For several decades prior, the MIT community has invested in improving $\mathrm{pK}-12$ education. In response to an institute-wide recommendation to define a K-12 strategy, a special interest group known as the pK-12 Action Group was established in 2016. ${ }^{1}$ This group joins members of different departments, laboratories, centers, and educational outreach student groups ${ }^{2}$ to develop programs, activities, and resources to engage $\mathrm{pK}-12$ teachers and students in meaningful educational experiences. As the pandemic disrupted education, the pK-12 community paused to consider, "How can our collective resources and ideas be made of service to the education community?"

This case study focuses on Full STEAM Ahead (FSA) - MIT's response to this educational crisis. Specifically, we present the design and development of two related Full STEAM Ahead initiatives. The first initiative was FSA learning packages - a curated collection of theme-based science, technology, engineering, arts, and mathematics (STEAM) learning activities for K-12 educators, students, and parents. From March to May, we released ten weekly learning packages on a newly designed website to share high-quality curricular materials for remote use. Members of the MIT community volunteered their time and efforts towards this initiative. The second initiative, Full STEAM Ahead into Summer (FSAIS), was conceptualized as the pandemic threatened to significantly disrupt summer learning opportunities for all students. Many summer programs for K-12 students, including our on campus programs, were canceled. Additionally, MIT students' summer job opportunities were limited due to the weakened US economy and uncertainty of safety in the workplace. To provide learning opportunities for local students and summer employment for MIT students, we created an online summer program where MIT students served as tutors and mentors to middle school students. FSAIS utilized resources curated from the spring FSA learning packages and other STEAM camp modules. Funding for the summer program came from a few sources. The MIT Chancellor Cynthia Barnhart's Office funded MIT student salaries; an internal donor funded the books included in materials kits. Money for the materials kits was raised from an external donor, the MIT Office of Government and Community Relations, and families who donated funds to cover the cost of those materials.

Full STEAM Ahead's mission is to create and share high-quality resources to facilitate digital and non-digital learning for K-12 and lifelong learners. By providing STEAM-based instructional materials and an open forum for users to share insights, we aimed to inspire a diverse global community of educators, students, and

\footnotetext{
${ }^{1}$ Institute-wide Task Force on the Future of MIT Education-Final Report: http://web.mit.edu/ future-report/TaskForceFinal_July28.pdf?

${ }^{2}$ To learn more about these pK-12 programs and activities visit: https://outreach.mit.edu/
} 
parents to find innovative and humanistic solutions to the challenges of learning at a distance. With this mission in mind, our theory of change is that we can improve K-12 remote collaborative learning experiences through strategically leveraging existing structures and projects within MIT and establishing partnerships with the local and international community. We are guided by two research questions:

1. How do groups at MIT collaborate internally and with schools and families to develop and support education efforts that reflect the mission of MIT?

2. What impact do these collaborations have on MIT students, K-12 students, and parents, and for improving future iterations of our work?

We first describe each initiative and then examine its impact on contributing MIT members and targeted learners. Finally, we explore the effects of those initiatives by analyzing survey data from participants and artifacts such as the website, modules, and student projects. In our discussion, we reflect on the advantages and challenges of each of these approaches and consider what aspects of our experiences could be transferable to other institutions.

\subsection{About MIT}

Since its founding in 1861, the Massachusetts Institute of Technology has remained committed to advancing knowledge and educating students in science, technology, and other areas of scholarship to best serve the nation and the world in the twentyfirst century. MIT currently has a student population of approximately 11,500 undergraduate and graduate students, awarding need-based scholarships to $59 \%$ of enrollees. The institute is well known for rigorous education and a faculty including Nobel Laureates and MacArthur Fellows. Furthermore, MIT is intentional about developing and supporting the next generation of learners in STEM education.

In 2014, an institute-wide task force initiated a deep self-assessment on the future of MIT Education focusing on the potential of MIT's resources and research to produce innovations in education based on "the educational model that has served the institute so well for so long." From this, a list of recommendations included a call to extend MIT's "mens et manus" style of pedagogy to the world, exploring means of certification to empower learners outside of the institute, collaboration with the global community to bring scaled change, and definition of an institutewide K-12 strategy. For years, many departments, labs, centers, and student groups had been actively supporting young learners who fell outside of the scope of higher education. However, in establishing a concentrated devotion from the auspices of the institute's administration and highlighting MIT's focus on K-12 education, our community has grown to collaborate, support, and innovate new practices. We have more fully realized the potential impact of higher education on establishing pathways for youth into STEM careers and fostering imaginative ways of thinking to bring both students and the world future success. 


\subsection{Bringing "Mind and Hand" to Remote Learning Environments}

The pedagogical spirit underlying these initiatives is embodied in MIT's motto, "mens et manus," which translates to "mind and hand." "Mind and hand" describes the combination of study and practice that characterizes the MIT approach towards meaningful learning. Fulfilling "mens et manus" involves rich learning opportunities to engage with content by collaboratively tackling problems, experimenting with multiple solutions to real situations, and learning by designing and building projects in alignment with one's interests.

MIT canceled all in-person spring and summer programs in response to the COVID-19 pandemic. Several MIT pK-12 groups responded to the disruption by pivoting to offer a diverse set of online programs. MIT Media Lab's Public Library Innovation Exchange (PLIX) and the Science and Engineering Program for Teachers (SEPT) are two adult learning programs delivered remotely. For high school students, programs included the Beaver Works Summer Institute (BWSI); the Saturday Engineering Enrichment and Discovery (SEED) Academy; BioBuilder; the Edgerton Center's Engineering Design Workshop (EDW); MIT Online Science, Technology, and Engineering Community (MOSTEC); and Lemelson-MIT Biotech in Action: Virtual Summer Lab. In addition to programs developed by MIT groups and centers, several programs created and managed by MIT students switched to remote delivery. These included the ESP Summer Program, involving two thousand students and approximately two hundred MIT student teachers, and the MIT CodeIt program, a six-week middle school program which teaches Scratch (a block-based programming language). Additionally, the MIT App Inventor's Coronavirus App Challenge received around one hundred project submissions from 20 countries, with participants between the ages of 8 and 72 .

This case study focuses on Full STEAM Ahead (FSA), a program that includes two parts: the spring Weekly Learning packages, and the online collaborative project-based summer program.

\subsubsection{Weekly Learning Packages}

When schools shut down, our team members connected with teachers to learn more about their challenges from transitioning to remote learning. State education agencies (SEA), who usually guide schools, administrators, and educators, had vastly different responses to the pandemic. Some SEAs provided detailed guidelines, while others had little information for educators (Reich et al. 2020a, b0). One of the greatest difficulties that teachers reported was the limited availability of high-quality learning materials. Teachers did not have the time to develop new materials from scratch and often did not know where to find pedagogically sound curricular materials online. Teachers were also overwhelmed in trying to communicate with students 
online and reaching the students with the most needs - themes paralleled in multiple research studies (Reich et al. 2020a, b). In response to the pandemic, many organizations offered curricular materials to teachers for free. Inundated with new curricular options, many educators could not simultaneously vet resources and adapt their classrooms and lives to remote instruction. Conversations with teachers inspired the conceptualization of MIT's Full STEAM Ahead learning packages.

The Full STEAM Ahead learning packages curated student-facing lessons with distribution over a span of several weeks. Learning packages were originally envisioned to be a weekly set of themed activities relieving some of the teachers' challenges. The release of learning activities over several weeks was intended to create a space where teachers, parents, or students could return each week to find new, well-designed materials on a variety of topics(Table 20.1).

Each package was intentionally designed to be open-ended, project-based, and theme-based with their activities for K-12 learners. The ten learning packages covered many topics in a variety of styles. For instance, the packages included activities that engaged learners in constructing a simulation of disease contagion (Package 1), designing musical instruments and compositions (Packages 4 and 8), and using recycled materials to build new inventions (Packages 2 and 6). Some packages also experimented with innovative ways of learner interaction, which includes allowing learners to ask researchers questions about life in space and the future of exploration virtually (Package 3) and asking learners to gather observations of their immediate surroundings and consider why things in and around their homes are the way they

Table 20.1 List of Full STEAM Ahead Weekly packages and their creators

\begin{tabular}{|c|c|}
\hline Weekly package & Contributor \\
\hline $\begin{array}{l}\text { Week 1: Modeling the } \\
\text { spread of disease }\end{array}$ & The Education Arcade \\
\hline $\begin{array}{l}\text { Week 2: Stepping into } \\
\text { invention education }\end{array}$ & Lemelson-MIT program (School of Engineering) \\
\hline $\begin{array}{l}\text { Week 3: Exploring and } \\
\text { living in outer space! }\end{array}$ & Space Exploration Initiative (MIT Media Lab) \\
\hline $\begin{array}{l}\text { Week 4: Making music and } \\
\text { sounds }\end{array}$ & Edgerton Center \\
\hline $\begin{array}{l}\text { Week 5: The world } \\
\text { around us }\end{array}$ & $\begin{array}{l}\text { Collaboration between MIT Open Learning, Education Arcade, } \\
\text { MIT Museum, Edgerton Center, MIT Sloan, Public Library } \\
\text { Innovation Exchange, MIT Environmental Solution Initiative, \& } \\
\text { J-WEL }\end{array}$ \\
\hline Week 6: Inventing matters! & Lemelson-MIT program (School of Engineering) \\
\hline $\begin{array}{l}\text { Week 7: Reveal! } \\
\text { Discovering science through } \\
\text { compelling images }\end{array}$ & MIT Museum \\
\hline $\begin{array}{l}\text { Week 8: Making Music \& } \\
\text { Sounds - II }\end{array}$ & Edgerton Center \\
\hline $\begin{array}{l}\text { Week 9: Artificial } \\
\text { intelligence! }\end{array}$ & Collaboration between personal robots group \& MIT app inventor \\
\hline $\begin{array}{l}\text { Week 10: Get creative with } \\
\text { math! }\end{array}$ & Lifelong Kindergarten Group (MIT Media Lab) \\
\hline
\end{tabular}


are (Package 5). Across all packages, there were common elements, such as interviews with experts and opportunities to share creations and collaborate through an online forum.

The analytic data described the demand for the packages and the general level of interest. Project examples we received through forums and emails demonstrated the students' level of engagement and the potential use of the materials, but this data was anecdotal, and our learner engagement was very limited. We reflected on this initial effort, the positive response from members of the MIT community, and our ability to collaborate as part of the response. From this, we saw an opportunity to engage more closely with learners, to scaffold learners' interests, and to advance our understanding of how middle school students learn STEAM concepts and develop skills through online learning experiences. Full STEAM Ahead into Summer was launched!

\subsubsection{Summer Program: Engaging Directly with Learners}

Full STEAM Ahead into Summer is a virtual summer program and academic enrichment opportunity that combines hands-on exploration, project design, and skill building (such as collaboration, problem-solving, and academic skills) in STEAM subjects. Designed for rising 7th, 8th, and 9th grade students in the state of Massachusetts, this three-week program involves approximately $4 \mathrm{~h}$ of activities and mentoring each day, incorporating materials from the Full STEAM Ahead website and open-source modules adapted for remote use from prior MIT STEAM camps (Bagiati et al., 2018).

To simultaneously serve MIT students and families and children in the Commonwealth of Massachusetts, we decided to develop a program where MIT students could mentor and teach middle school students through a collaborative, hands-on, remote learning program. We hoped to leverage our existing resources in the form of FSA learning packages and student expertise while developing a STEAM enrichment program for children most affected by the pandemic.

We recruited 33 MIT undergraduate students, graduate students, and recent graduates to be mentors for this pilot program. Two of these mentors were promoted to program coordinators, responsible for serving as the primary points of contact between the MIT staff, MIT student mentors, and the program participants as well as their parents and guardians.

Seven training sessions made the mentors familiar with the activities and modules they would facilitate over each of the three-week sessions and hosted faculty, K-12 educators, MIT digital learning fellows, and our staff to share advice. These sessions included an introduction to problem-based learning inspired by "The Three Acts of a Mathematical Story," an introduction to the specific STEAM modules, online teaching tips, culturally responsive teaching, a training to involve all students in remote learning, an introduction to Design Thinking, and how to lead a book club around "The Lost Tribes" by Taylor-Butler (2018) (Gewin, 2020; Hammond, 2014; Meyer, 2011; Razzouk \& Shute, 2012). 


\section{Elements of the Program}

The switch to online learning has been especially challenging for students with a lower socioeconomic status, who are at a greater risk of falling behind academically (Goldstein, 2020). We wanted to make sure the program served learners from different backgrounds and interests, but above all, those who could benefit from the different elements of the program (math tutoring, project modules, etc.). The initial phase of the recruitment focused on partner schools that serve traditionally underrepresented students in STEM fields - including Black and Hispanic students - students who qualify for free or reduced lunch, English language learners, and students who will be the first in their families to attend college (see Table 20.2).

We spoke with teachers, administrators, and parents at the Community Charter School of Cambridge (CCSC) and incorporated their input into the design of the program. For example, parents advised us that they would prefer a three-week program (as opposed to a six-week program) and that it would be important to make

Table 20.2 FSA Summer Program Schedule

\begin{tabular}{|c|c|c|}
\hline Time & Element & Brief description \\
\hline $\begin{array}{l}10: 30- \\
10: 40\end{array}$ & $\begin{array}{l}\text { Program-wide } \\
\text { meeting }\end{array}$ & Schedule reminders, shout-outs, community building \\
\hline \multirow[t]{2}{*}{$\begin{array}{l}10: 40- \\
11: 10\end{array}$} & \multirow[t]{2}{*}{ Choice time } & $\begin{array}{l}\text { Modeled after MIT Educational Studies Program's SPLASH } \\
\text { and SPARK offerings, described as a "teaching and learning } \\
\text { extravaganza" where MIT student volunteers teach a topic of } \\
\text { their choosing on a specified weekend in November }\end{array}$ \\
\hline & & $\begin{array}{l}\text { Our mentors' offerings included Coding in Scratch and } \\
\text { Python, Greek Mythology, Creative Writing, Micro:Bit } \\
\text { Basics, TikTok Dancing, LGBTQ Diversity, Making Origami } \\
\text { Animals, etc. }\end{array}$ \\
\hline \multirow[t]{4}{*}{$11: 20-12$} & \multirow{4}{*}{$\begin{array}{l}\text { Academic time } \\
\text { (math tutoring, book } \\
\text { club on Fridays) }\end{array}$} & 5-7 students per group \\
\hline & & $\begin{array}{l}\text { Informed by the Massachusetts prerequisite content standards } \\
\text { and interviews from teachers and parents }\end{array}$ \\
\hline & & $\begin{array}{l}\text { Math problems are based on "three ACT math", an inquiry- } \\
\text { based strategy where students analyze a visual image or } \\
\text { video using a three-part, story-telling structure (i.e., } \\
\text { invitation, discussion, and resolution) }\end{array}$ \\
\hline & & $\begin{array}{l}\text { Friday Book Club: Students read and discuss The Lost Tribes, } \\
\text { a book for middle school students by Christine Taylor-Butler, } \\
\text { an MIT alumna }\end{array}$ \\
\hline $12-1$ & Lunch break & \\
\hline \multirow[t]{4}{*}{$\begin{array}{l}1-3 \text { (2 on } \\
\text { Fridays) }\end{array}$} & \multirow{4}{*}{$\begin{array}{l}\text { Project-based } \\
\text { learning time (guest } \\
\text { speaker on Fridays) }\end{array}$} & $\begin{array}{l}\text { 10-12 students per group, engaging in a variety of hands-on } \\
\text { modules }\end{array}$ \\
\hline & & $\begin{array}{l}\text { Topics included Exploring Outer Space with CubeSats, } \\
\text { Music Instruments \& Data-Sonifying Your Data, The World } \\
\text { Around Us-Observational exploration, Building Wind } \\
\text { Turbines, and Two-Stage Water Rockets }\end{array}$ \\
\hline & & $\begin{array}{l}\text { Culminated in a week-long design thinking workshop in } \\
\text { which students develop their own projects }\end{array}$ \\
\hline & & $\begin{array}{l}\text { Generative, allowing space for creativity and innovation (not } \\
\text { just replication) }\end{array}$ \\
\hline
\end{tabular}


activities engaging, as many of their students were tired of remote learning. Our recruitment team also utilized existing partnerships between MIT and local Cambridge Public Schools, Prospect Hill Academy in Cambridge/Somerville, and Greater Lawrence Technical High School. Our outreach included multiple meetings with school leaders and teachers to describe our program in depth and confirm support from the school. We requested that schools allow students to keep borrowed technology over the summer so that students, regardless of income level, could access our program.

We discovered a high demand for access to summer opportunities. Over the course of two weeks, we received $800+$ applications for the pilot program. Admissions prioritized students from our "partner schools;" over half of our participants came from schools that serve underrepresented students. Every student who applied from a partner school was granted a seat. We filled the remaining 130 seats through a random lottery of completed applications. We accepted 341 students (6th-9th grades) from 57 cities across the state of Massachusetts (see Fig. 20.1). The first session began on July 6th and included 166 students from 47 towns. The second session, which started on August 3rd, included 125 students from 40 towns.

Because of the hands-on nature of the project modules, each participant and MIT Mentor received their own materials kit. Early on, we decided that the kits were necessary for the program's success and equity for all participants, so they were provided free of charge. To make the most of limited resources, we decided to order materials and self-assemble 350 kits in a socially distanced setting, a collegue's backyard. We offered three pickup locations for kit distribution, and the remaining boxes were mailed to participants.

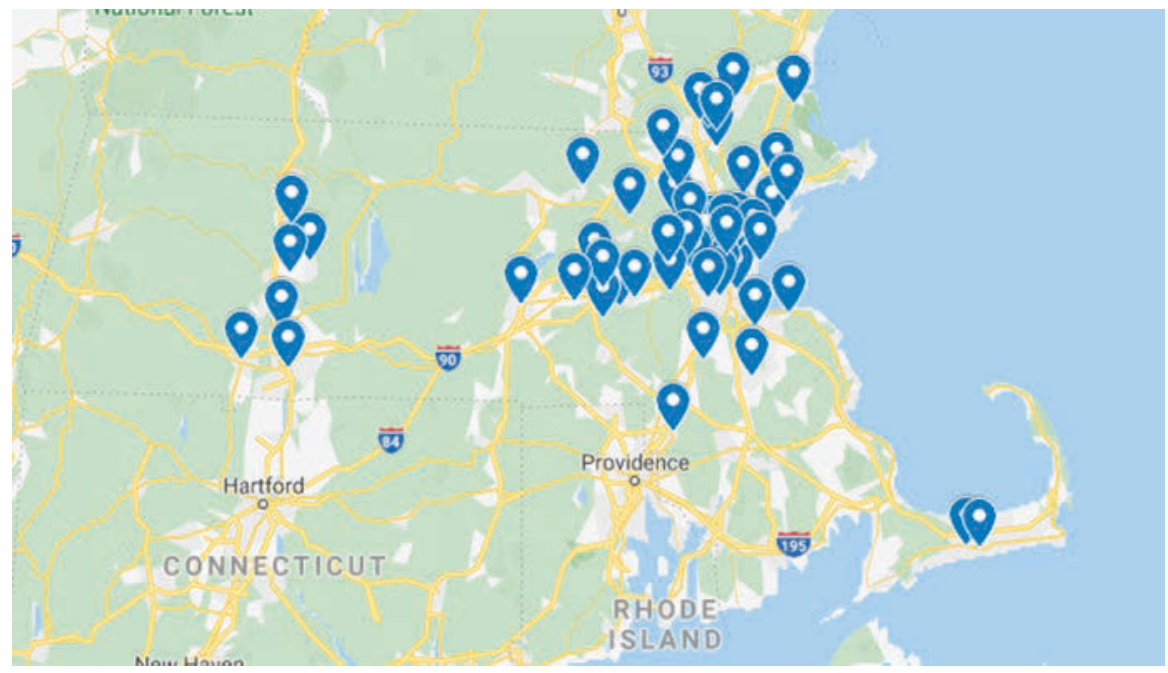

Fig. 20.1 Map of student participant locations in Massachusetts 
So far, we have described two remote learning initiatives - FSA learning packages and FSAIS -developed in response to the pandemic. In the remainder of this paper, we draw on data from the initiatives to investigate two research questions:

1. How do groups at MIT collaborate internally and with schools and families to support education efforts?

2. What impact do these collaborations have on MIT students, K-12 students, parents, and in helping us improve our work?

\subsection{Method}

The research study includes a mixed-method, convergent research design, with qualitative and quantitative data gathered simultaneously during the project (Fetters et al., 2013). Our methods are similar for both Full STEAM Ahead Weekly Learning Packages and Full STEAM Ahead into Summer initiatives. We invited participants from FSA and MIT community members to complete a survey about the package creation and distribution process; we also invited parents and middle school students to complete a postexperience survey about the FSAIS program. Our research has been designed with minimal impact on the day-to-day experience of the program and to maintain confidentiality and anonymity among respondents. It is also covered under COUHES E-2470 for the FSA project and COUHES Protocol \#: 2007000196 for the FSAIS project. We calculated frequencies and descriptive statistics for quantitative data from survey data and qualitative review of the artifacts designed by students during the program, open-ended survey responses, and informal parent/student feedback.

While our summer program had an academic component, we did not expect to see significant changes in student performance in math and reading over just 3 weeks. Research on similar outreach programs indicates that programs of about a 30-h duration can impact students' knowledge of the program topics, as well as attitudes, interests, and beliefs in STEM (Cappelli et al., 2019; Newton et al., 2018). Thus, we hypothesized that this program would increase students' interest in and motivation to explore STEAM topics, their self-efficacy in mathematical problemsolving, and their knowledge of and self-efficacy for open-ended, project-based work (Chen, 2012; Chen \& Usher, 2013). Our sample at the time of writing this article included 50 parents and 50 students, about one-third of those who had enrolled in Session 1. The demographics and age for the students in this sample appear in Table 20.3. 
Table 20.3 Demographics of student and parent respondents

\begin{tabular}{l|l|l|l|l|l}
\hline Race & $\mathrm{N} / \%$ & Ethnicity & $\mathrm{N} / \%$ & Grade in Sept 2020 & N/\% \\
\hline White & $22(44 \%)$ & Not Hispanic & $37(74 \%)$ & 7 th & $22(44 \%)$ \\
\hline Asian & $8(16 \%)$ & Hispanic & $11(22 \%)$ & 8 th & $10(20 \%)$ \\
\hline African American & $13(26 \%)$ & Prefer not to say & $2(4 \%)$ & 9 th & $18(36 \%)$ \\
\hline More than one & $4(8 \%)$ & & & & \\
\hline Prefer not to say & $3(6 \%)$ & & & & \\
\hline
\end{tabular}

\subsection{Results}

This case study includes responses from the MIT community about their experiences and contributions to FSA learning packages and results from the first session of the summer program; at the time of this chapter's writing, the second session had just begun. We plan to maintain our research into the summer program and share these findings in future publications.

\subsubsection{MIT Community Collaboration in Learning Packages}

FSA learning packages provided an opportunity for the MIT community to mobilize their capacities and efforts towards common goals. In what follows, we describe:

1. How the community self-organized within a very short span of time to mount this initiative.

2. Results from data analytics about the global reach of learning packages.

3. How this collaboration supported the MIT community members' individual goals.

\subsubsection{Rapid Mobilization of Capacity and Efforts to Launch the Learning Packages}

Each package represented the combined efforts of several groups or labs and individuals across MIT. The groundwork for the development of the packages was largely established through the development of Package 1, "Modeling the Spread of Disease," which was assembled and released within 5 days of project initiation. In the development of this package, members of the MIT pK-12 community selforganized into four sub-teams. The sub-teams were fluid and changed based on the specific week, but a small core team of individuals volunteered their time toward package development across the ten-week span. The four sub-teams worked on specific tasks involved in package completion: 
1. Ensuring that each week had a package lead, coordinating with package leads, and ensuring that packages-in-progress aligned with our broader pedagogical goals.

2. Designing and developing activity materials for the package and interviewing experts. In some weeks, this team consisted of individuals from a single group that was already involved in STEM education outreach (e.g., Package 10), and in others, a package was formed out of a collaboration between two or more groups (e.g., Package 5).

3. Preparing and transferring the activity materials and videos onto the Full STEAM Ahead website.

4. Disseminating packages through writing and sharing media releases.

\subsubsection{Data Analytics About Global Reach of the Packages}

Our analytics revealed a total of $130,000+$ pageviews and 45,000+ unique viewers for the learning packages over the course of the 10-week package release. The packages were accessed by learners in 150 countries around the world, with most visitors from the United States, Canada, India, the United Kingdom, Brazil, Japan, Australia, Mexico, Turkey, and Hong Kong. Around 35\% of site visits were from returning viewers. Data from the first week of August shows that the most popular packages have been "Stepping into Invention Education" (Package 2) and "Modeling the Spread of Disease" (Package 1). Other popular packages include "Making Music and Sounds Part I" (Package 4), "Exploring and Living in Outer Space!" (Package 3), and "Getting Creative with Math" (Package 10) (Fig. 20.2).

We received some examples of artifacts produced by students from Full STEAM Ahead forums and emails. One of the projects came from a young boy who shared

Top Package Pages on MIT Full STEAM Ahead (March - July 2020)

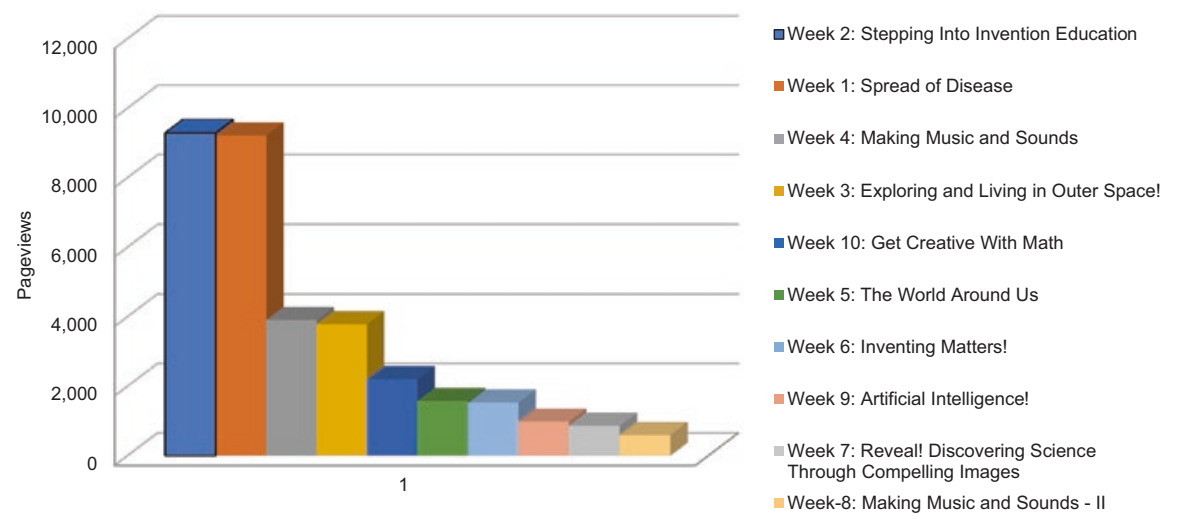

Fig. 20.2 Top page hits from the MIT Full STEAM Ahead website 


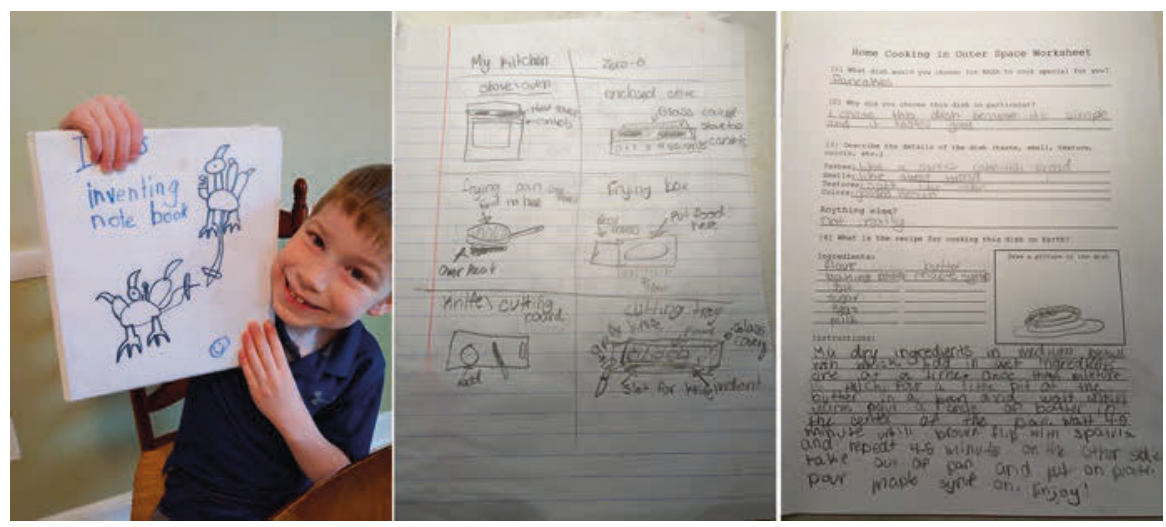

Fig. 20.3 Artifact examples from Full STEAM Ahead package activities

his picture of the invention journal, developed during "Stepping into Invention Education" (Package 2). A second example came from a middle school girl who was engaged with the "Future of Space Food" activities that were part of "Exploring and Living in Outer Space!" (Package 3) (Fig. 20.3).

We also heard from teachers, who adapted some of the resources and activities for use during the spring semester and added them to their remote teaching.

I love the activities in the Full STEAM ahead modules! There are a lot of resources being thrown at us [teachers] right now but I do find the Full STEAM ahead ones stand out in terms of being actually useful. — Educator from Columbia, SC

\subsubsection{How This Collaboration Supported the MIT Community Members' Individual Goals}

We received 20 responses from members of the MIT community who contributed to the weekly packages. We have at least two responses from eight out of the ten packages. Packages 7 and 10 had only one response (Fig. 20.4).

The top factors that motivated members of the community to participate in the FSA consisted of helping others (teachers, parents, and students) and collaborating with other members of the MIT community. Approximately $95 \%$ of respondents reported that they felt that they met those goals $(\mathrm{N}=20$ responses). The only respondent who expressed that their goals were not met explained that "the goals of content creation were met, but we really don't know anything about who we reached or how satisfied they were."

About $44 \%$ of responses mentioned the need to have more visibility of the impact ( $\mathrm{N}=9$ responses). Some respondents also reported that the FSA team did not connect them with teachers. 

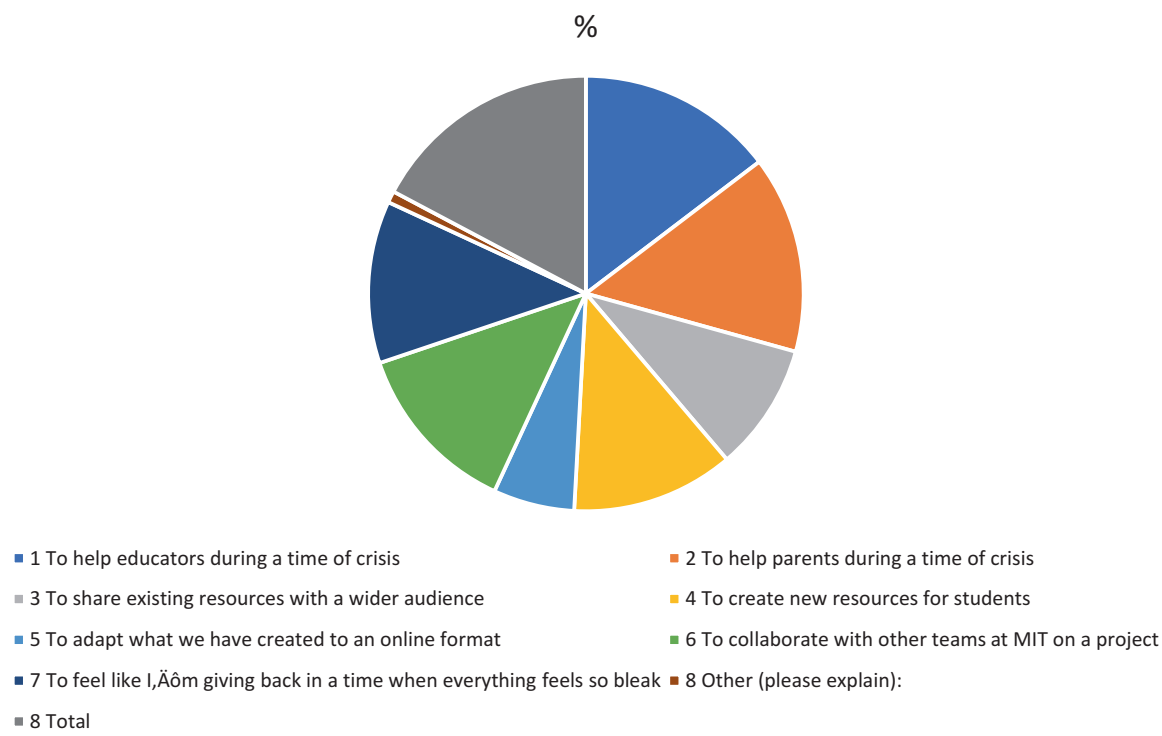

Fig. 20.4 Reasons for participating in developing FSA learning packages

Content creation, dissemination, and collaboration among members of the MIT community were some of the most important outcomes from the weekly packages. When reporting about participation, $90 \%$ of the respondents said that they were able to reach a broader audience, and $85 \%$ said it helped them both develop ageappropriate materials and collaborate with other MIT community members $(\mathrm{N}=20$ respondents). Specifically, the respondents reported that the FSA team helped them disseminate their materials (90\%), provide feedback (85\%), or help by adding new resources (45\%). Looking deeper at collaboration among members of the MIT community, we know some collaboration happened during package creation and continued even after the package launches (50\%). About half of the respondents (55\%) reviewed other packages, so that all packages were reviewed by between $2-6$ community members. Further opportunities and aspirations for collaboration were proposed by the respondents, who mentioned ideas such as "combine technical, research and subject matter expertise/offerings with others to have greater impact," "collaborating on research projects," and "blending content/cross-referencing content," among other comments.

\subsubsection{Summer Program}

Students and parents were asked to rate different aspects of the summer program: the materials kit, hands-on projects, choice time, math tutoring, and the selected book. The responses are summarized in Fig. 20.5, grouped by aspects with student feedback on the left column and parent feedback on the right. 


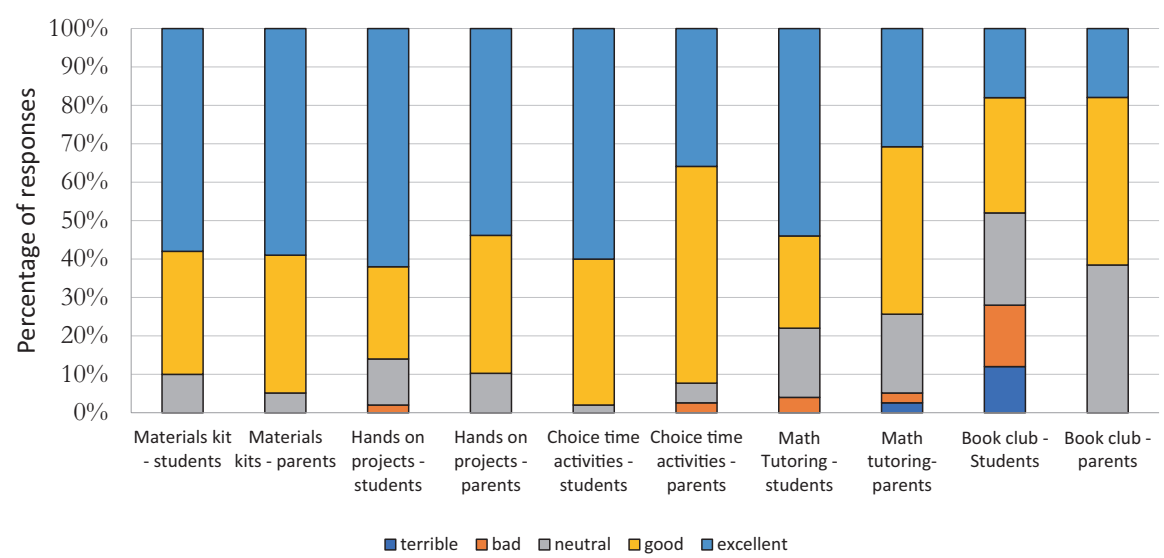

Fig. 20.5 Students' and Parents' Feedback on the Summer Program

Parents and students gave the material kits and the hands-on projects the highest ratings. Some students and parents recognized that being online made project building more difficult and were especially appreciative of having hands-on projects. One parent appreciated that "[...]my child was able to do hands-on activities while doing distance learning - the ability to not be stuck in a chair during distance learning."

One student wrote that what they liked best was "the way they made Zoom meetings fun, starting to learn Python in choice time, and building and designing handson projects despite the fact that we were all remote on Zoom."

Another important part of the program was how mentors encouraged collaboration among students. Students responded that they felt like they were part of a community of peers and MIT mentors. Students were able to share ideas and work together through the online format, indicating that community interaction was an important part of their remote learning experience (Fig. 20.6).

Students' open-ended comments reinforced the importance of interaction with others. One student wrote, "I enjoyed how I got to interact with other people during quarantine and had fun during this program." Another commented, "Something that I liked from the program is the way we interact which is cool to see online because this didn't happen in regular school." Parents also commented on the level of engagement their children had in the program. One parent wrote, "My son used a scientific approach to build and design independently. It was amazing to see such engagement in an online learning platform." Another commented, "My child was willing to get out of bed every day and participate; he did not do this with remote school. He absolutely loved his math tutor and has not stopped talking about it! Well done!" The MIT mentors were essential to the success of the program and were described as "friendly," "fun to talk to," "inspiring," "patient," and "phenomenal." We are learning a lot from the MIT mentors' reflections and will present those data in future research. 


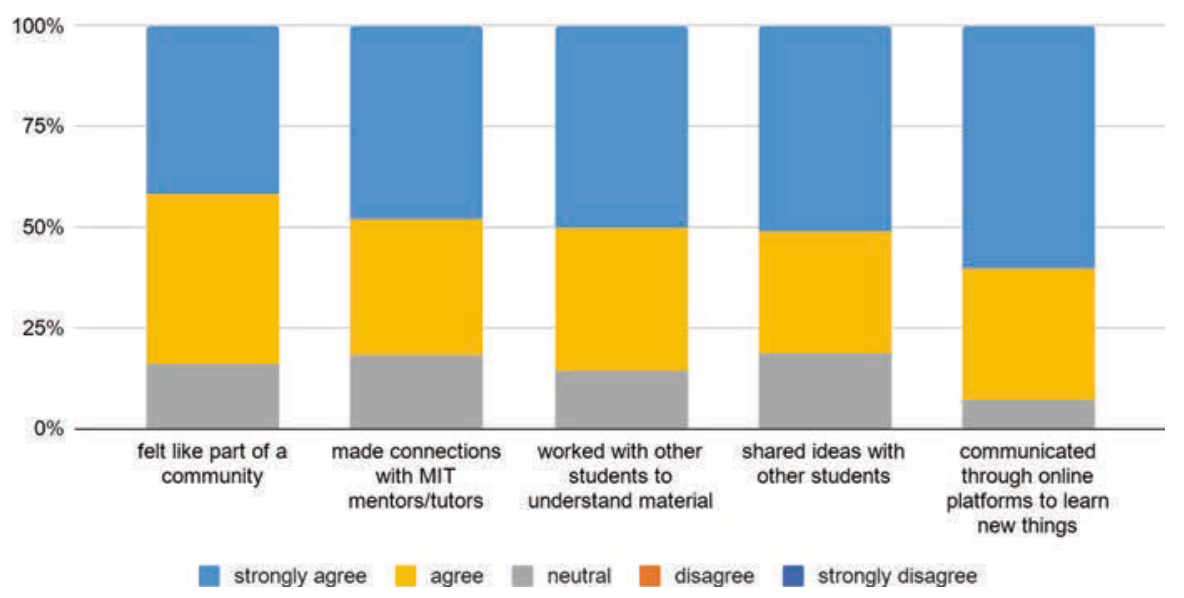

Fig. 20.6 Students' response to online engagement and collaboration during FSAIS $(\mathrm{N}=50)$

While there is still a lot of uncertainty about education in the coming months, it is certain that online and remote learning will continue to be an essential delivery system for learners. We will continue to investigate these ideas during Session 2 and will continue our research on how to develop and support active, hands-on, and collaborative learning in remote settings.

\subsection{Discussion}

This case study demonstrates two approaches toward the same goal of improving pK-12 remote collaborative learning experiences between the university and community in response to the global pandemic. In this discussion, we consider the benefits and drawbacks for each and consider how these findings may inform other institutions who are interested in engaging with the pK-12 community. We believe our results support our hypothesized theory of change, which was that a minds-on and hands-on approach can be applied to remote learning experiences by strategically leveraging existing structures and projects within MIT and through external partnerships.

Our initial response was to gather a range of existing resources for the Full STEAM Ahead website. The FSA website presented the range of resources from existing MIT pK-12 groups. The initiative also prompted the creation of weekly packages, which created opportunities for MIT staff and faculty to collaborate across groups to create and distribute weekly updates to the community via social media. Website analytics display that the content was accessed by people around the globe. We had some, but little, activity in the online forums. Beyond the analytics and some user emails, we are uncertain of the website's impact on educators and 
learners. However, we know that this initiative helped bring together people at MIT and resulted in a product that is easy to maintain and sustain.

Our summer response was more focused, labor-intensive, and resource-intensive but still drew from existing projects. We were able to reach out to teachers and recruit students from our existing partnerships with local schools. These relationships allowed us to connect with teachers and parents for a "needs assessment" to determine what types of activities would be helpful to their students. In some cases, we were able to arrange for students to keep the technology they had borrowed from their school to support access and equity.

The existing curriculum was adapted from prior work and from the website weekly packages for the remote project-based learning experience. We also modified existing processes to fit with the online format. For example, we created shared Google Docs; two coordinators reviewed the reflections each day for themes, great ideas, questions for the group, and "shout-outs" for the group meeting. Results from this program suggest middle school students and parents valued the learning experience and connections with MIT mentors.

In reflecting on our Full STEAM Ahead efforts, we believe that there are some key ideas that are applicable beyond MIT. The first idea is to leverage existing resources whenever possible. We were able to pull together a website and a summer program quickly in part because we already had established the network of people doing pK-12 activities and because we identified a plan of action and invited the MIT community to contribute. The second idea is to embrace and find resources to support cross-institutional partnerships. We were able to leverage school partnerships and relationships that we had cultivated both from the STEP teacher certification program and the Office of Government and Community Relations. This initiative enabled us to work alongside members of other MIT programs who we may not have connected with outside of Full STEAM Ahead. We believe that funding from the Chancellor is one indication of support for cross-institutional partnerships and hope that the value in these partnerships will continue to be recognized and encouraged by the university. Third, we encourage individuals to cultivate pK-12 communities within their institution. MIT has several pK-12 initiatives, and we share ideas and awareness of each other's work through monthly informal "pK-12 lunches." During these lunches, we eat together, invite a speaker from inside or outside the MIT community to share their work in pK-12, and engage in a discussion. This community was the cornerstone of the Full STEAM Ahead initiative and the source of the core team, and it consolidated the resources used for the website and summer program. Building community through hosting these types of lunches is an easy entry point into building a community of pK-12 interested groups and individuals that can be ready to activate for the next global crisis, with the hope that we will not need to do that anytime soon. 


\subsection{Conclusion and Next Steps}

We have met the challenge of remote learning with innovative strategies that we hope will advance MIT's mission across a distance. While designing the learning experiences, we have purposefully maintained the hands-on nature of the activities and allowed students the freedom to develop and test new ideas, fail, and iterate. In the spring, we purposefully designed our weekly packages to be accessible to many audiences by creating projects that mostly needed commonly available items such as paper, cardboard, markers, string, and aluminum foil. In the summer, we continued this strategy by assembling and distributing materials kits to all students who participated in the Full STEAM Ahead into Summer program.

As we continue to adapt to the pandemic's challenges, we will still document and share our successes and challenges, cultivating further reflection and the development of promising ideas. With this in mind, we think about three critical pathways forward: teaching and mentoring opportunities for MIT students, STEAM projects and materials for students, and teacher/parent support and development.

For fall 2020 and spring 2021, MIT has committed to fund every undergraduate student in an experiential learning project. Faculty and staff from MIT departments have developed a range of opportunities for MIT students that are collectively grouped under a few themes: Public Service and Social Impact, Innovation and Entrepreneurship, Global Opportunities, Teaching and Learning, and the longstanding Undergraduate Research Opportunity Program (UROP). With the expansion of experiential learning this fall, we are seeking ways for the program to provide a model for others and how we can leverage this experience to provide an umbrella that helps to support other teaching and learning experiences in a rigorous way. With administrative support, we have established the Undergraduate Teaching Opportunities Program (UTOP) as an umbrella organization to provide trainings, pedagogical development, seminars, and structure to programs across the campus, drawing upon lessons from past efforts and recent efforts during the age of remote learning.

As we craft new methods for valuable learning environments, we have continued to honor our motto: creating and sharing high-quality learning experiences and engaging the minds and hands of pK-12 students.

Acknowledgements We are thankful to all our colleagues, partners, and the MIT groups, centers, and departments that supported this work provided amazing content and donated their time to make this happen in a very short time frame. A special thank you to those who provided generous donations to the Full STEAM Ahead into Summer program, the families, and the MIT Office of Government and Community Relations for helping cover the cost of the materials, and to MIT Chancellor Cynthia Barnhart for championing this project and funding the MIT student mentors (Fig. 20.7). 


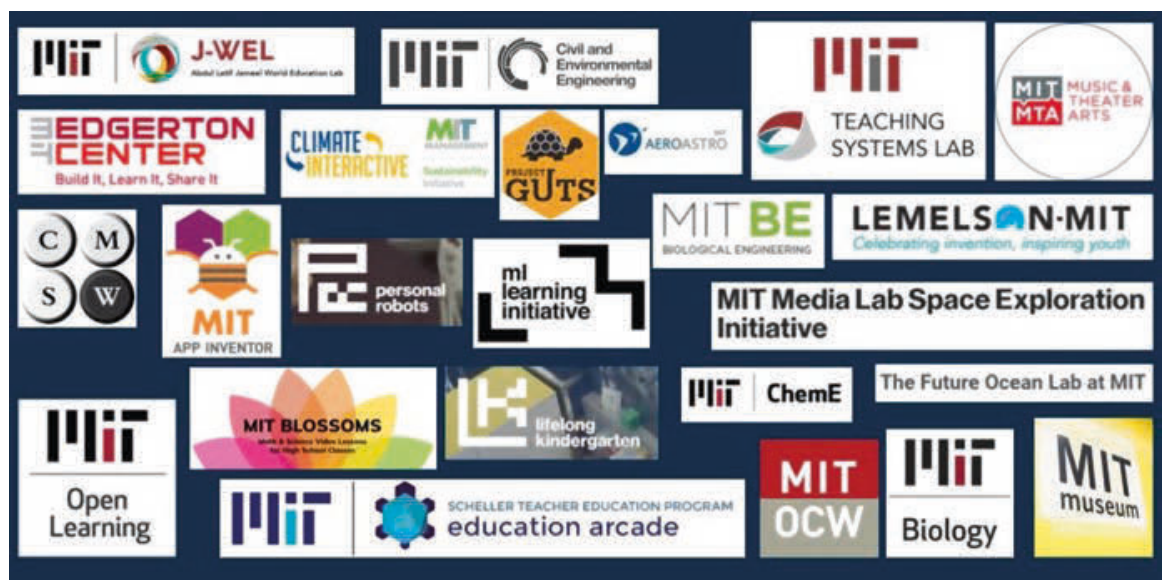

Fig. 20.7 A compilation of MIT contributor logos

\section{References}

Bagiati, A., Urrea, C., \& Diaz, J. (2018). The STEAM Camp: Introducing Sustainable Development Goals in K-12. In 46th SEFI Conference, At Copenhagen, Denmark. Retrieved November 21, 2019, from https://www.researchgate.net/publication/328517287_The_STEAM_Camp_ Introducing_Sustainable_Development_Goals_in_K-12

Cappelli, C. J., Boice, K. L., \& Alemdar, M. (2019). Evaluating university-based summer STEM programs: Challenges, successes, and lessons learned. J. STEM Outreach, 2, 1-12.

Chen, J. A., \& Usher, E. L. (2013). Profiles of the sources of self-efficacy among middle and high school science students. Learning and Individual Differences, 24, 11-21.

Chen, J. A. (2012). Implicit theories of ability, epistemic beliefs, and science motivation: A personcentered approach. Learning and Individual Differences, 22, 724-735.

Fetters, M. D., Curry, L. A., \& Creswell, J. W. (2013). Achieving integration in mixed methods designs-Principles and practices. Health Services Research, 48(6pt2), 2134-2156.

Gewin, V. (2020). Five tips for moving teaching online as Covid-19 takes hold. Nature, 580(7802), 295-296.

Goldstein, D. (2020). The Class Divide: Coronavirus Teaching at Two Schools, Public and Private. New York Times. June 5, 2020. https://www.nytimes.com/2020/05/09/us/coronavirus-publicprivate-school.html

Hammond, Z. (2014). Culturally responsive teaching and the brain: Promoting authentic engagement and rigor among culturally and linguistically diverse students. Corwin Press.

Hodges, C., Moore, S., Lockee, B., Trust, T., \& Bond, A. (2020). The difference between emergency remote teaching and online learning. Educause Review, 27.

Kuhfeld, M., \& Tarasawa, B. (2020). The Covid-19 slide: What summer learning loss can tell us about the potential impact of school closures on student academic achievement. NWEA white paper. https://www.nwea.org/content/uploads/2020/05/Collaborative-Brief_Covid19-SlideAPR20.pdf

Meyer, D. (May 11, 2011). The three acts of a mathematical story. dy/dan https://blog.mrmeyer. com/2011/the-three-acts-of-a-mathematical-story/ 
Newton, S. H., Alemdar, M., Moore, R. A., \& Cappelli, C. J. (2018, June). An investigation of students' experiences in a K-12 invention program (Evaluation). In 2018 ASEE annual conference \& exposition. https://peer.asee.org/29796

Razzouk, R., \& Shute, V. (2012). What is design thinking and why is it important? Review of Educational Research, 82(3), 330-348.

Reich, J., Buttimer, C. J., Fang, A., Hillaire, G., Hirsch, K., Larke, L. R., Littenberg-Tobias, J., Moussapour, R., Napier, A., Thompson, M., \& Slama, R. (2020a, April 2). Remote Learning Guidance From State Education Agencies During The COVID-19 Pandemic: A First Look. https://doi.org/10.35542/osf.io/437e2

Reich, J., Buttimer, C. J., Coleman, D., Colwell, R. D., Faruqi, F., \& Larke, L. R. (2020b, July 22). What's Lost, What's Left, What's Next: Lessons Learned from the Lived Experiences of Teachers during the 2020 Novel Coronavirus Pandemic. https://doi.org/10.35542/osf.io/8exp9 Taylor-Butler, C. (2018). The Lost Tribes: Safe Harbor. Move Books.

Dr. Claudia Urrea is the Senior Associate Director for pK-12 at the MIT Abdul Latif Jameel World Education Lab (J-WEL), and she also has a visiting scholar position with the Lifelong Kindergarten group at the MIT Media Lab. During the last 7 years, she has worked on different initiatives such as the Institute-wide Task Force on the Future of MIT Education, the MIT Online Education Policy Initiative, and the MIT pK-12 Action Group. Additionally, Dr. Urrea founded the MIT STEAM camp, which brings MIT's learning approach to middle school students and teachers in international locations, and co-founded Full STEAM Ahead, a virtual program that combines hands-on exploration, project design, and skill building in STEAM subjects. Before joining MIT Open Learning, Urrea worked at the Interamerican Development Bank as a consultant in the education sector and at the One Laptop Per Child organization as Director of Learning. For the past 25 years, Dr. Urrea has helped multiple governments and nongovernment agencies - The New York Academy of Sciences, Schlumberger Excellence in Education Development, and International Development Research Centre, among others - to empower and support schools and communities of learners to evolve from traditional pedagogy to progressive learning environments.

Kirky DeLong has over 20 years of experience in the development of learning technologies, online laboratories, and open-source projects. During her time at MIT, she has worked on many projects involving a broad range of technologies, including the MIT iLab Project, which developed online laboratories enabling students to access real instruments online that can be shared around the world; the MIT-Haiti Project, which promotes teacher professional development through active learning and Kreyòl language in STEM disciplines; and the Connected Learning Initiative (CLIx) project, which aims to improve the professional and academic prospects of high schools students from underserved communities in India.

Joe Diaz is an MIT graduate and advocate of hands-on STEAM activities for K-12 students. As an alumnus of MIT's Scheller Teacher Education Program, he has spent time both inside and outside the classroom, developing programs for kids who have little access to quality education. For the past 4 years, he has worked with MIT Open Learning to bring MIT's learning approach to elementary, middle, and high school students and teachers via the STEAM Camp project to a variety of locations including Hong Kong, China, and Greece.

Dr. Eric Klopfer is Professor and Director of the Scheller Teacher Education Program and the Education Arcade at MIT. He is also the Head of the Department of Comparative Media Studies and Writing, and faculty advisor for MIT's J-WEL World Education Lab. His research has focused on technology and pedagogy for growing the understanding of science, technology, engineering, and mathematics (STEM) and systems. His work uses a design-based research methodology to span the educational technology and learning ecosystem, from the design and development of new technologies to professional development and implementation. Much of Klopfer's research has 
focused on computer games and simulations for building an understanding of STEM as well as connecting programming to topics of student and teacher interest. He is the co-author of the books, "Adventures in Modeling," "The More We Know," and "Resonant Games," as well as the author of "Augmented Learning." His lab has produced software (from casual mobile games to the MMO: The Radix Endeavor) and platforms (including StarLogo Nova and Taleblazer) used by millions of people, as well as online courses that have reached hundreds of thousands. Klopfer is also the cofounder and past president of the nonprofit Learning Games Network.

Meredith Thompson draws upon her background in science education and outreach as a research scientist and lecturer for the Scheller Teacher Education Program. Dr. Thompson's research interests are collaborative learning, STEM educational games, and virtual and simulated environments for learning STEM topics. She has a bachelor's degree in chemistry from Cornell University, a master's degree in science and engineering education from Tufts University, and a doctorate in science education from Boston University. She has two current projects: The Collaborative Learning Environments for Virtual Reality (CLEVR) is creating a cross-platform collaborative game about cellular biology and INSPIRE is a group of education professors who are using games and simulations in teacher preparation. Thompson uses those games and simulations when she teaches the STEP course: "Understanding and Evaluating Education."

Aditi Wagh is a Research Scientist in the Scheller Teacher Education program at MIT. She received her doctoral education in Learning Sciences from Northwestern University after which she spent 3 years as a postdoctoral scholar at Tufts University. As part of her research, she designs computational tools that enable students to author ideas and express their thinking for STEM learning in classrooms and informal learning environments. She investigates how these tools can support students' learning of complex systems and engagement in STEM practices. Her research has been funded by organizations such as the National Science Foundation, Tufts University, and the Davis Foundation. Her research projects have ranged from designing and studying maker education in schools and after-school programs, developing computational modeling toolkits and curricula for K-12 education, redesigning undergraduate biology labs to integrate computational modeling, and developing interactive museum exhibits for the Field Museum.

Jenny Gardony is the Program Manager of the Scheller Teacher Education Program at MIT. In her role, she co-teaches the Introduction to Education Classes ("Looking Forward and Looking Back on Education" and "Understanding and Evaluating Education"), and she mentors, supports, and evaluates upperclassmen earning their teacher certification in secondary STEM fields. Jenny's other work in the STEP Lab includes teacher professional development, particularly around student-centered inquiry-based education, and community outreach to broaden access and participation in STEM fields. Prior to coming to MIT, Jenny taught middle and high school math for 10 years. While teaching, she served as a mentor for new teachers, a grade level leader, and founded/led a student drama club. She received her BA from Tufts University and her MEd from Cambridge College.

Emma Anderson is a research scientist in the Scheller Teacher Education Program at MIT. She received her PhD from the University of Pennsylvania's Graduate School of Education. She holds an MA from the University of Buffalo in geology and a BA from Smith College in sociologyanthropology. Her research centers around science, art, making, and play. Her research has explored learning biology through a complex systems lens, bridging science and math learning with coding, shifting teachers' pedagogical practices, and more. Prior to her doctoral studies, she worked at Baltimore Woods Nature Center as an environmental educator bringing science lessons into urban kindergarten through sixth-grade classrooms and leading summer campers around the woods. 
Rohan Kundargi As the K-12 Community Outreach Administrator within MIT's Office of Government and Community Relations, Dr. Rohan Kundargi works assiduously to connect MIT's K-12 opportunities with young learners in the Cambridge-Boston metro area. A first-generation Indian American, Rohan was raised in Northern California before embarking on careers in research and higher ed. Before his career in community engagement, Dr. Kundargi was an academic geoscientist, obtaining earth science degrees from UCLA and Boston University, where he enjoyed investigating Earth's mysteries using a myriad of techniques: from shooting lasers through diamonds to creating complex 3-D models to simulate how volcanoes erupt. After graduate school, he moved to Eastern Washington to run Science in Action! Gonzaga University's largest STEM outreach program to the second-largest school district in the state, before joining MIT OGCR in 2018.

Open Access This chapter is licensed under the terms of the Creative Commons Attribution 4.0 International License (http://creativecommons.org/licenses/by/4.0/), which permits use, sharing, adaptation, distribution and reproduction in any medium or format, as long as you give appropriate credit to the original author(s) and the source, provide a link to the Creative Commons license and indicate if changes were made.

The images or other third party material in this chapter are included in the chapter's Creative Commons license, unless indicated otherwise in a credit line to the material. If material is not included in the chapter's Creative Commons license and your intended use is not permitted by statutory regulation or exceeds the permitted use, you will need to obtain permission directly from the copyright holder.

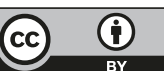

